\title{
Microsporidium arthuri n. sp., parasite of Pangasius sutchi (Pangasiidae, Siluroidea) in South-East Asia
}

\author{
Jiří Lom ${ }^{1}$, Iva Dyková ${ }^{1}$, Faizah Shaharom ${ }^{2}$ \\ ${ }^{1}$ Institute of Parasitology, Czechoslovak Academy of Sciences, České Budéjovice, Czechoslovakia \\ ${ }^{2}$ Faculty of Fisheries, University Pertanian Malaysia in Serdang, Selangor, Malaysia
}

ABSTRACT: A microsporidian infection due to Microsporidium arthuri n.sp., has been observed in Pangasius sutchi from South-East Asia. The parasite forms uninucleate spores averaging $3.1 \times 2.1 \mu \mathrm{m}$, variable in shape, mostly rounded pyriform but often curved. The exospore has a pattern of mosaic-like small fields. Developmental stages were not observed. In heavy infections, large parasite masses destroyed parts of the musculature but host reaction was mostly limited to phagocytosis of spores.

Among vertebrates, fish constitute the class most extensively parasitised by microsporidia. Thus far, if the species recorded in Canning \& Lom (1986) are supplemented by recent descriptions, a total of 81 named and 30 unnamed species are known, belonging to the genera Glugea. Heterosporis, Ichthyosporidium, Loma, Microgemma, Jirovecia, Pleistophora, Spraguea, Tetramicra, Thelohania and the collective group Microsporidium. The 2 species assigned to the genus Thelohania should probably be reclassified in some other genus, and single species of the genus Jirovecia may have been a parasite of the prey animals. Unnamed species constitue one third of the total number of fish microsporidia. Species assigned to the collective group Microsporidium account for almost one fifth of the total number of species in fish. A proper generic assignment for these species is impossible because only mature spores and no developmental stages are known. Such is the situation of new species which we found during a short stay of the senior author at the University Pertanian Malaysia in Serdang. We publish its description to stimulate further research on the little-known microsporidia and other fish parasites in this region.

Materials and methods. Pangasius sutchi were purchased from a pet shop in Serdang, state of Selangor in Malaysia. They had been imported from Bangkok, Thailand. Squash preparations from all body organs were examined and fresh spores were observed and photographed. Smears were treated with periodic acid-Schiff (PAS) reagent for polysaccharides and with Feulgen nuclear stain.

Three heavily infected specimens of Pangasius sutchi were sampled for histology. Pieces of infected tissue were fixed in $10 \%$ buffered formalin processed for embedding in paraffin wax, sectioned at $5 \mu \mathrm{m}$ and stained with haemotoxylin-eosin and Giemsa stains. Samples from 3 more fish were fixed in cold $2 \%$ osmic acid in $0.1 \mathrm{M}$ cacodylate buffer and embedded in Epon-Araldite. Ultrathin sections, double stained with uranyl acetate and lead citrate, were observed in a Philips 420 B electron microscope operated at $80 \mathrm{kV}$.

Results and discussion. Twenty-five fish were examined. In addition to a Hexamita species found in one specimen and spores of a Myxobolus sp. in 4 specimens, infection due to a microsporidium was found in 9 specimens in the trunk muscles. In 4 fish with heavy infections white foci were not visible through the skin.

Each focus consisted of masses of spores. The spores were of variable shape (Fig. 1), mostly pyriform, often curved, comma-shaped, or ellipsoidal to cylindrical, and some were almost subspherical. The anterior end was always narrower than the posterior one. The size was $3.1(2.3$ to 3.8$) \times 2.1(1.8$ to 2.2$) \mu \mathrm{m}(\mathrm{n}=40)$. The posterior vacuole occupied one half to one third of the spore length, depending on the spore shape. The PASpositive polar cap appeared as a tiny dot and the Feulgen reaction showed a single nucleus. Electron microscopy revealed little of the spore contents except for 6 turns of the coiled isofilar polar tube (Fig. 2). The exospore was raised into a mosaic of irregular fields separated by grooves which were rectangular in transverse section (Figs. 3 and 4 ). 

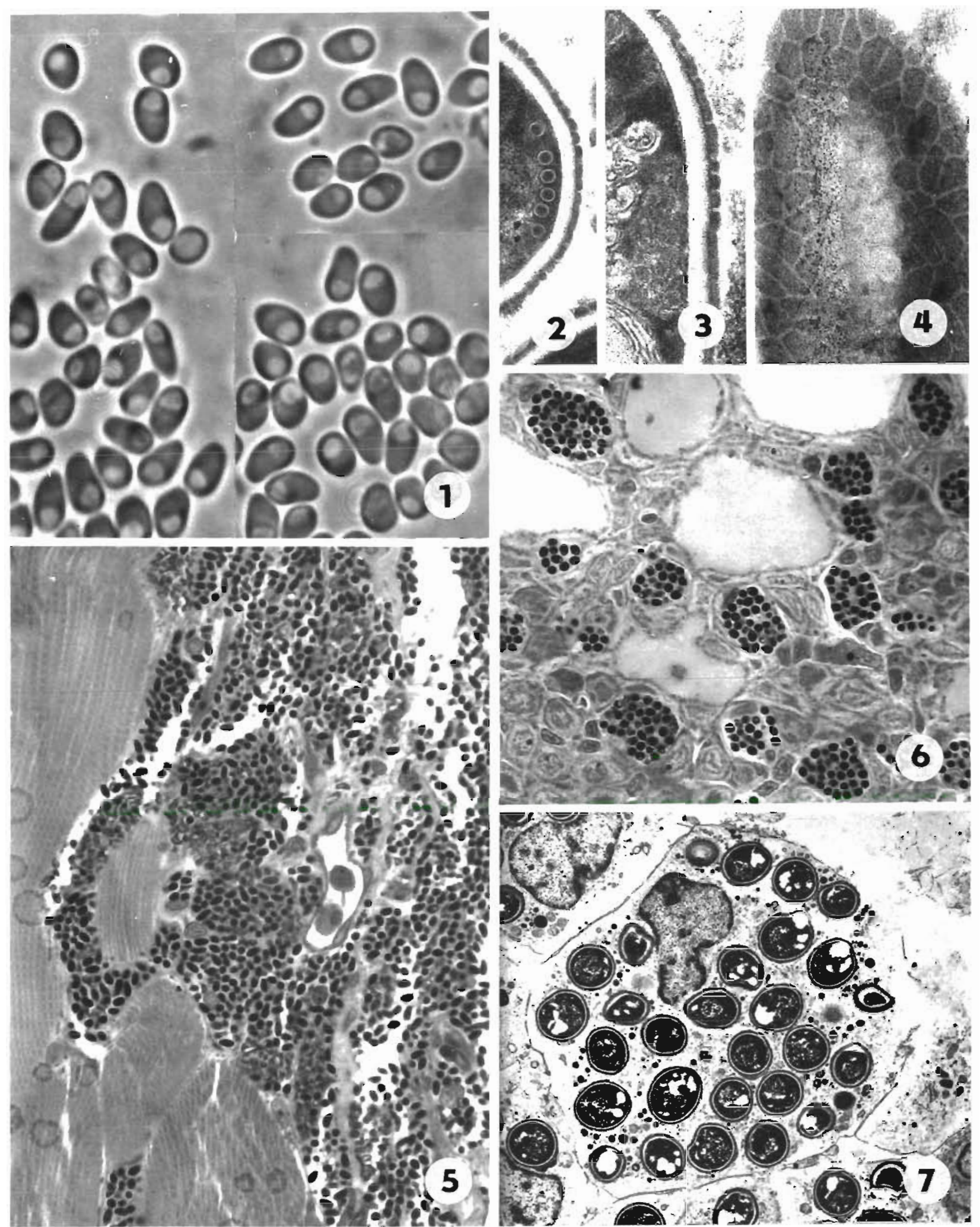

Figs. 1 to 7. Microsporidum arthuri n.sp. Figs. 1,5 and 6 are light micrographs; Figs. 2 to 4 and 7 are electron micrographs. Fig. 1 . Fresh spores, $\times 2600$. Fig. 2. Periphery of a mature spore with transverse sections of the 6 coils of the polar tube, $\times 23000$. Figs. 3 and 4. Transverse and tangential section of the mosaic-like exospore thickenings, $\times 30000$ and $\times 23000$, respectively. Fig. 5 . Spore mass in the muscilature, $\times 900$. Fig. 6 . Spores in macrophages in the epidermis, $\times 850$. Fig. 7. A macrophage with ingested 
In the mass of spores freshly released from the dissected muscle, structures similar to subpersistent sporophorous vesicles containing a large number of spores were observed but no evidence of these structures was found in the sectioned material. No developmental stages were detected. Histopathological studies revealed only giant aggregates of apparently free spores in skeletal musculature and in myosepta among the blocks of skeletal muscles. Large parts of dorsal and lateral muscles were replaced by a mass of spores (Fig. 5) which sometimes even surrounded vertebrae and separated some of the myomeres and muscle fibers from each other. Small aggregates of spores were also found in subcutaneous connective tissue, in corium and epidermis. The only host reaction observed was phagocytosis of spores. The appearance of macrophages was uniform with cytoplasm containing many spores (up to 30 spores were visible in section) (Fig. 7) Some of the macrophages with ingested spores were also observed in blood vessels. The spore-filled macrophages were scattered among the epithelial and specialized alarm cells of epidermis (Fig.6). Some spores were observed in the moment of release from stratified squamous epithelium.

The absence of spore foci in organs other than muscles indicates that trunk muscles are the site of infection. The occasional sighting of sporophorous vesiclelike structures in fresh material is of no help in generic assignment, since they may be found both in Pleistophora and Glugea. In the former, though, the sporophorous vesicles mostly persist long after the spores have matured (see samples in Canning \& Lom 1986) unlike those for Pangasius sutchi. Although the generic assignment requires further study, a perusal of existing descriptions indicates that this is a new species. No microsporidia have been described from freshwater cyprinids with comparable spore structure and picture of infection. In Microsporidium takedai (Awakura 1974) the host belongs to a different family (salmonids) and the clinical image differs, although the spores, equally small, are similar. Spores of variable shapes were described for Glugea machari by Jirovec (1934). Curved, comma shapes are characteristic of the 'slender' spores of Spraguea lophii (Loubès et al. 1979) but all other features are different. We consider that the parasite should be designated as a new species, for which the name Microsporidium arthuri n.sp. is proposed. The name of the collective group is applied in accord with Sprague (1977) and the species is named

Responsible Subject Editor: Professor W. Körting, Hannover, F.R. Germany after a leading ichthyoparasitologist in the region, Dr J. Richard Arthur.

There are safe differential features available for this species, especially the variable spore shapes, the 6 turns of the polar tube and the surface pattern carved in the exospore layer of the spore wall. In most species of fish (and other) microsporidia, the spore surface is smooth or artificially irregularly wrinkled due to fixation. In the 'slender' spores of Spraguea lophii, a pattern of ridges was observed (Lom \& Weiser 1972) different from that observed in the present species. Such surface ornamentation may be of diagnostic value.

In spite of extensive damage to the muscle in the region infected, the fish did not reveal any signs of distress. Curiously, there were no connective tissue capsules around the spore masses, as are commonly found in Pleistophora infections (Dyková \& Lom 1980). No fibroblast activity was observed. Also, the myophagous histiocytes seemed to be absent at the stage of infection that we observed. An interesting phenomenon was the transport of spores, ingested in macrophages across the epidermis to the outside milieu, reminiscent of a similar process in e.g. Myxobolus cyprini in cyprinid fish (Dyková \& Lom 1988). It was not determined whether the sojourn in macrophages rendered the spores nonviable.

\section{LITERATURE CITED}

Awakura, T (1974). Studies on the microsporidian infection in salmonid fishes. Sci. Rep. Hokkaido Fish Hatchery 29. $1-96$

Canning, E. U., Lom, J. (1986). The microsporidia of vertebrates. Academic Press, London

Dyková, I., Lom, J. (1980). Tissue reaction to microsporidian infection in fish hosts. J. Fish Dis. 3: 265-283

Dyková, I., Lom, J. (1988). Review of pathogenic myxosporeans in intensive culture of carp (Cyprinus carpio) in Europe. Folia Parasit. 35: 289-307

Jírovec, O. (1934). Octosporea machaři n.sp., aus der Leber von Dentex vulgaris. Zool. Anz. 106: 61-64

Lom, J., Weiser, J. (1972). Surface pattern of some microsporidian spores as seen in the scanning electron microscope. Folia Parasitol. (Praha) 19: 359-363

Loubès, C., Maurand, J., Ormières, R. (1979). Etude ultrastructurale de Spraguea lophii (Doflein, 1898), microsporidie parasite de la Baudroie: essai d'interpretation du dimorphism sporal. Protistologica 15: 34-54

Sprague, V. (1977). Annotated list of species of microsporidia In: Bulla, L. A., Cheng, T C. (eds.) Comparative pathology 2, Systematics of the Microsporidia. Plenum Press, New York, p. 31-334

Manuscript first received: July 31, 1989

Revised version accepted: November 28, 1989 